\title{
CRUSTAL STRUCTURE AND SURFACE-WAVE DISPERSION IN AFRICA*
}

\author{
By Frank Press, Maurice Ewing, and Jack Oliver
}

\section{INTRODUCTION}

IN 1953, through coöperation of the Bernard Price Geophysical Institute of the University of the Witwatersrand and the University of Natal, a Columbia University-type long-period seismometer ( $T o=15 \mathrm{sec} ., \mathrm{Tg}=75 \mathrm{sec}$.) was installed in the seismological observatory of the University of Natal at Pietermaritzburg, Union of South Africa. This instrument was well situated for receiving surface waves from the shock in northern Algeria of September 9, 1954, and the aftershock next day, which was of such intensity that its seismogram supplemented that of the original shock for the larger phases. The dispersion of the Rayleigh waves from these seismograms can be measured with greater precision than has been practicable heretofore for continents, because the path is longer $(7,890 \mathrm{~km}$.) than any which has been available for a long-period vertical instrument, and is remarkably free from obvious anomalies such as major mountain ranges. The scarcity of suitable seismograms for the study of Raleigh-wave dispersion along continental paths is due to the fact that suitably placed long-period vertical seismographs have not been available until recently.

\section{Data}

According to B.C.I.S. the epicenter of the main shock of September 9, 1954, $H=01: 04: 37$, was $36^{\circ} 17^{\prime} \mathrm{N}, 1^{\circ} 28^{\prime} \mathrm{E}$, and the Pasadena magnitude was $63 / 4$. The aftershock of September 10,1954, $H=05: 44: 05$, was placed at $36.6 \mathrm{~N}, 1.3 \mathrm{E}$, Praha magnitude 6.2. The Rayleigh-wave portion of both seismograms is reproduced in figure 1 . Time is marked in figure 1 as minutes after the origin time, and the beginnings of the Rayleigh-wave train, the $\mathrm{Lg}$ train, and the $\mathrm{Rg}$ train are indicated. Also marked is a group of waves which is interpreted as an Rg phase reflected from the continental margin. The Rayleigh-wave train for the main shock shows clearly the typical Rayleigh-wave dispersion for continental paths which has been commonly studied in the past. With the arrival of the Lg phase, the apparent intensity of which is greatly reduced by the decrease in sensitivity of the seismograph for short periods, it becomes more difficult to read the ordinary Rayleigh waves, but they can be read by shifting from the main shock to the aftershock at a point about halfway between the arrival of $\mathrm{Lg}$ and that of Rg, entirely out to the beginning of Rg. The waves of intermediate frequency arriving between Lg and $\mathrm{Rg}$ are probably a part of the Lg train. Rg begins abruptly and with great amplitude, as may be seen very clearly on the seismogram of the aftershock. The inverse dispersion in this phase is clearly demonstrated for the first time on this seismogram. The point at $44 \mathrm{~min} .45 \mathrm{sec}$. after the origin time just prior to the arrival of a new shorter-period reflection train is taken to represent an Airy phase corresponding to the minimum value of group velocity for Rayleigh-wave propagation across continents. The short-period waves (which likewise show a lengthening of period with time) just following this Airy phase are interpreted as a reflection from the continental boundary at some point such that the path of the reflected wave exceeds the great circle

\footnotetext{
* Manuscript received for publication March 25, 1955.
} 


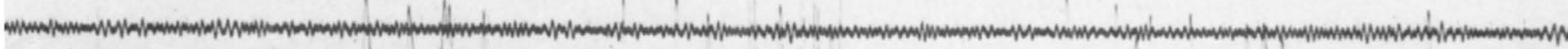
Ninem, (n)

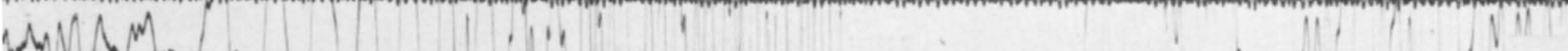

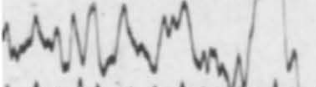

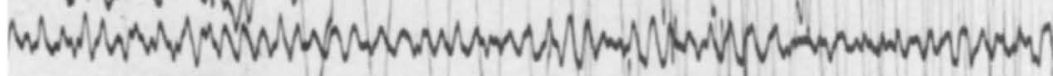

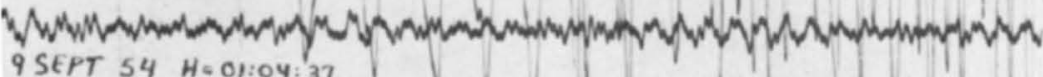
9SEPT $54 \mathrm{H}=01: 04: 37$ |
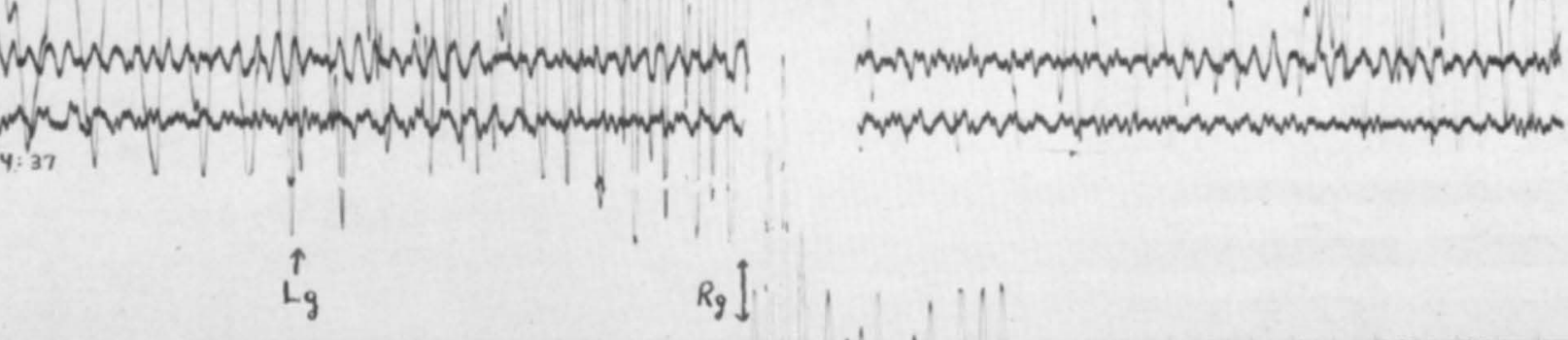

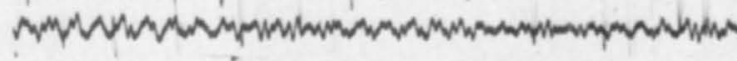

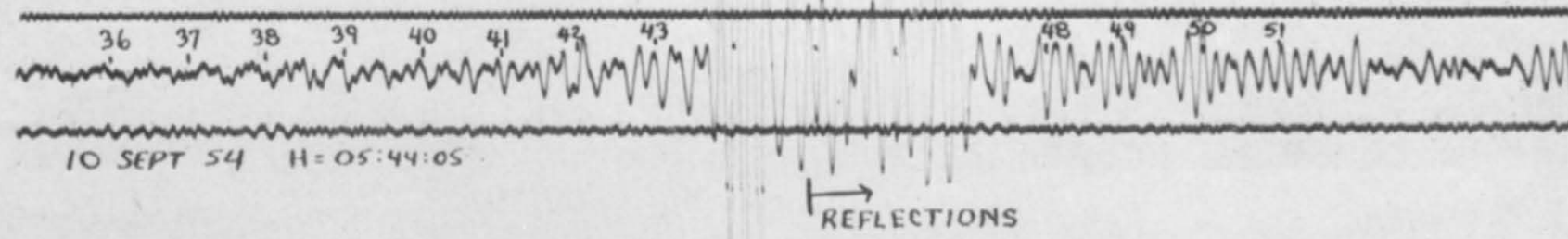

Fig. 1. Pietermaritzburg seismograms of the Algerian earthquake of September 9, 1954, and aftershock of September 10, 1954. Travel time in minutes is indicated. 
path by approximately $250 \mathrm{~km}$. These last-mentioned waves will not be considered in our study of the dispersion.

Similarly the surface waves arriving during the next 10 or 15 minutes are interpreted as scattering and reflections involving even larger increases in path length.

The method of reading data for calculating the dispersion is that which has been used, for instance, in an earlier paper. ${ }^{1}$ The times of zero deflection of the trace are

TABLE 1

Dispersion Data

\begin{tabular}{|c|c|c|c|}
\hline \multicolumn{2}{|c|}{$\begin{array}{c}\text { September } 9,1954 \\
\triangle=7,890 \mathrm{~km} .\end{array}$} & \multicolumn{2}{|c|}{$\begin{array}{c}\text { September } 10,1954 \\
\triangle=7,925 \mathrm{~km} .\end{array}$} \\
\hline$T$ sec. & $U \mathrm{~km} / \mathrm{sec}$. & $T^{\prime}$ sec. & $U \mathrm{~km} / \mathrm{sec}$ \\
\hline $31.3 \ldots \ldots$ & 3.33 & $10.8 \ldots \ldots \ldots$ & 3.02 \\
\hline$\ldots \ldots$ & 3.36 & $11.4 \ldots \ldots \ldots \ldots$ & 3.00 \\
\hline 32.1 . & 3.39 & $12.3 \ldots \ldots \ldots \ldots$ & 2.98 \\
\hline 32.7 . & 3.42 & $14.2 \ldots \ldots \ldots \ldots$ & 2.97 \\
\hline 33.2 & 3.45 & $16.1 \ldots \ldots \ldots \ldots$ & 2.96 \\
\hline $33.6 \ldots \ldots$ & 3.48 & $19.5 \ldots \ldots \ldots \ldots$ & 2.95 \\
\hline $34.1 \ldots \ldots \ldots$ & 3.51 & $20.2 \ldots \ldots \ldots \ldots$ & 2.94 \\
\hline $34.5 \ldots \ldots$ & 3.54 & $22.3 \ldots \ldots \ldots$ & 3.05 \\
\hline $35.4 \ldots \ldots \ldots$ & 3.57 & $22.6 \ldots \ldots \ldots$ & 3.07 \\
\hline $37.5 \ldots \ldots \ldots$ & $3.6 \mathrm{I}$ & $23.4 \ldots \ldots \ldots$ & 3.10 \\
\hline $40.8 \ldots$ & 3.64 & $24.1 \ldots \ldots \ldots$ & 3.12 \\
\hline $42.0 \ldots$ & 3.68 & $24.5 \ldots \ldots \ldots \ldots$ & 3.14 \\
\hline $45.1 \ldots$ & 3.71 & $25.0 \ldots \ldots \ldots$ & 3.17 \\
\hline $47.8 \ldots$ & 3.75 & $25.8 \ldots \ldots \ldots$ & 3.20 \\
\hline 50.3 & 3.78 & $26.5 \ldots \ldots \ldots$ & 3.22 \\
\hline 55.7 & 3.82 & $27.2 \ldots \ldots \ldots$ & 3.25 \\
\hline $62.5 \ldots$ & 3.86 & $28.0 \ldots$ & 3.27 \\
\hline \multirow[t]{5}{*}{$71.5 \ldots$} & 3.89 & $\ldots \ldots \ldots$ & 3.30 \\
\hline & & $\ldots \ldots \ldots$ & 3.33 \\
\hline & & $\ldots \ldots \ldots \ldots$ & 3.36 \\
\hline & & $\ldots \ldots \ldots \ldots$ & 3.39 \\
\hline & & $32.0 \ldots \ldots \ldots \ldots$ & 3.42 \\
\hline \multirow{3}{*}{$\cdots:$} & & $32.2 \ldots \ldots \ldots \ldots$ & 3.45 \\
\hline & & $32.8 \ldots \ldots \ldots \ldots$ & 3.48 \\
\hline & & $33.2 \ldots \ldots \ldots \ldots$ & 3.51 \\
\hline
\end{tabular}

read and plotted against wave number. Periods for a series of arrival times are read as slopes of the resulting curve. The seismogram of the main shock was used for the principal Rayleigh-wave dispersion from about 33 minutes to about 40 minutes after origin time. The seismogram of the aftershock was used from about 37 minutes 30 seconds to about 45 minutes after origin time. The dispersion data thus obtained are presented in table 1 and plotted in figure 2. Also plotted in figure 2 are the data for a path across the United States given by Brilliant and Ewing, ${ }^{2}$ obtained by the

${ }^{1}$ Maurice Ewing and Frank Press, "Crustal Structure and Surface-Wave Dispersion, Part II; Solomon Islands Earthquake of July 29, 1950," Bull. Seism. Soc. Am., 42:315-325 (1952).

${ }^{2}$ Renée Brilliant and Maurice Ewing, "Dispersion of Rayleigh Waves across the United States," Bull. Seism. Soc. Am., 44: 149-158 (1954). 
method of using a number of stations on the great circle path from a shock in the southwest Pacific. Also plotted is a point indicating the short-period limit of mantle Rayleigh waves from Ewing and Press. ${ }^{3}$ A theoretical curve is drawn, based on the calculations of Jeffreys, ${ }^{4}$ in which the elastic constants originally used by Jeffreys have been changed to agree with the most recent determinations of crustal structure from explosion and rockburst data. ${ }^{5}$ This curve assumes a homogeneous crust $35 \mathrm{~km}$. thick with shear velocity $3.51 \mathrm{~km} / \mathrm{sec}$. overlying a homogeneous mantle with shear

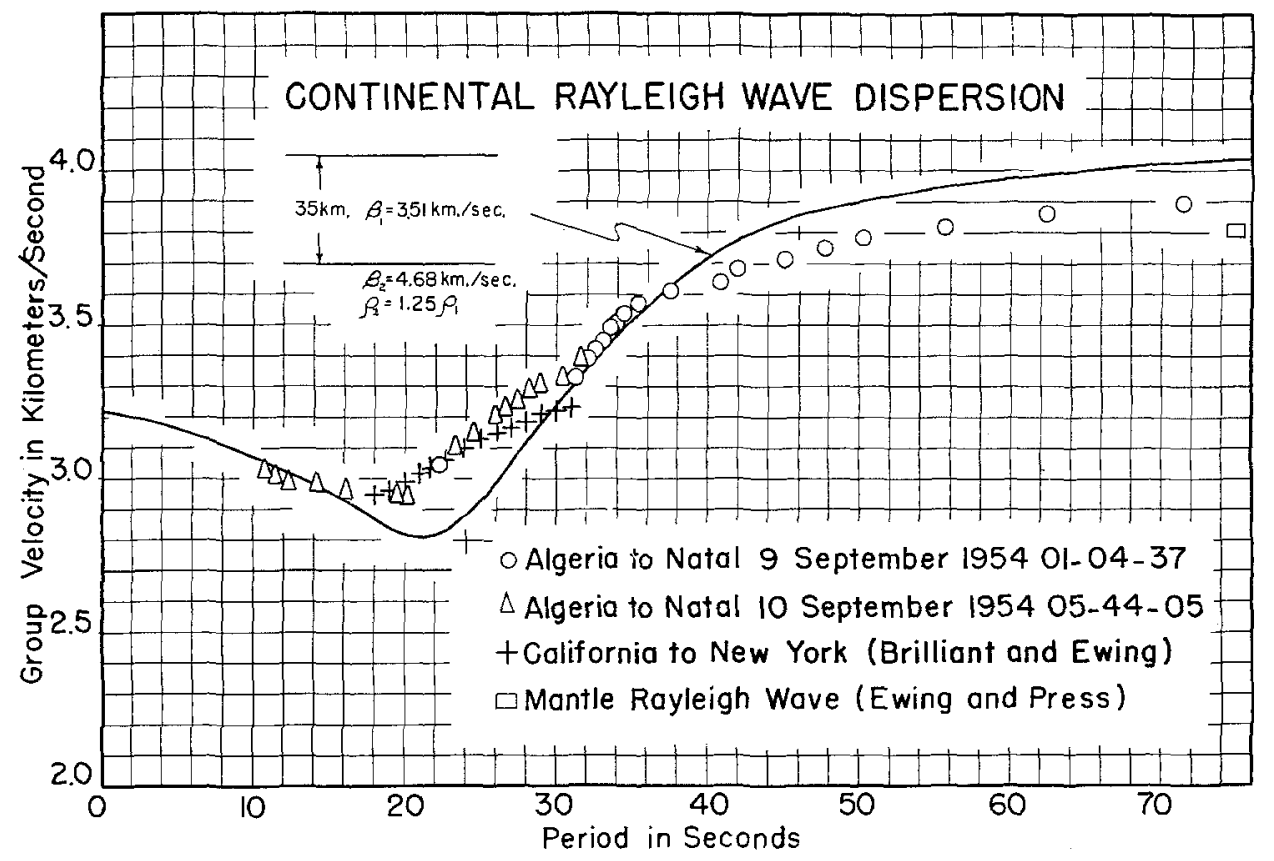

Fig. 2. Observed dispersion of Rayleigh waves crossing Africa compared to theoretical dispersion for standard crust.

velocity $4.68 \mathrm{~km} / \mathrm{sec}$. and density 1.25 times that of the crust. The shear vleocity in the crust was chosen as the best value given by Lg observations in North America. ${ }^{6}$ Båth recently reported an $\mathrm{Lg}$ velocity of $3.54 \mathrm{~km} / \mathrm{sec}$. for Eurasian paths. ${ }^{7}$

\section{DisCUSSION}

The experimental Rayleigh-wave dispersion curve in figure 2 extends from periods of 10 sec. to at least 70 sec., based on data from a single shock and its aftershock, and is of high precision, affording a unique opportunity for comparison of observations with theory. The completeness of the curve results from the fact that the path

${ }^{3}$ Maurice Ewing and Frank Press, "Mantle Rayleigh Waves from the Kamchatka Earthquake of November 4, 1952," Bull. Seism. Soc. Am., 44:471-479 (1954).

4 Harold Jeffreys, "Surface Waves of Earthquakes," Mon. Not. Roy. Astron. Soc., Geophys. Suppl., 3: 253-261 (1935).

5 For summary see Beno Gutenberg, "Wave Velocities in the Earth's Crust," in "Crust of the Earth," Geol. Soc. Am., Special Papers 6\% (1955).

"Frank Press and Maurice Ewing, "Two Slow Surface Waves across North America," Bull. Seism. Soc. Am., 42:219-228 (1952).

7 Markus Bäth, "The Elastic Waves $\mathrm{Lg}$ and $\mathrm{Rg}$ along Euro-Asiatic Paths," Ark. f. Geofysik, $2: 295-342(1954)$. 
was long and not complicated by obvious anomalous regions. The seismograph had broad response characteristics, permitting registration of waves covering a wide range of periods, and the aftershock provided, in effect, a low sensitivity trace, permitting coverage of a wide range of amplitudes.

The agreement in group velocity between the present data for Africa and those from North America is noteworthy for the period range 18 sec. to 31 sec., which was the limit of data available by the method of Brilliant and Ewing. The diserepancies are all less than $0.1 \mathrm{~km} / \mathrm{sec}$. This agreement supports the view that, despite differences in elevation and topography, the continents of Africa and North America are identical in crustal structure along the paths of the surface waves used in these studies. Although this uniformity had been pointed out by us earlier, ${ }^{8}$ these data have higher precision than those usually available, and they add certainty to the conclusion that the continents all act like ideal plates with the same properties. This fact is a powerful one for excluding from further consideration many theories of the formation and growth of continents.

Over the entire range from periods of 10 sec. to periods of $75 \mathrm{sec}$. the discrepancy between the observed points and the curve given by the simple theory is quite good by the current standards of continental Rayleigh-wave studies, but the present observations are of sufficient precision that it is possible to accept the discrepancies as real and quantitative, and to endeavor to make quantitative explanations of them.

For periods greater than 38 sec. the observed points fall below the theoretical curve by an amount which increases to slightly more than $0.1 \mathrm{~km} / \mathrm{sec}$. The fact that the observed points fall below the curve over about 1 octave of periods in the long-period range suggests that the discrepancy is due to a change of properties with depth in the mantle. Theoretical curves based on a theory which takes the mantle velocity gradient into account are not available. Experimentally, the effect of an increase of velocity with depth in the mantle on the dispersion curve appears to be of this nature and of this magnitude. ${ }^{9}$ The adjustment of the theoretical curve must be made by using a velocity gradient instead of by decreasing the velocity in the outermost part of the mantle, because the values of 8.18 and $4.68 \mathrm{~km} / \mathrm{sec}$. for compressional and shear waves are firmly established in explosion seismology studies. As expected, the observed dispersion curve from the present study connects with the short-period end of the mantle Rayleigh-wave dispersion curve of Ewing and Press ${ }^{10}$ at a period of about 75 sec., forming a broad maximum of group velocity at about $3.8 \mathrm{~km} / \mathrm{sec}$, before the descent to the next minimum at a period of about 225 sec. and a group velocity of about $3.54 \mathrm{~km} / \mathrm{sec}$. This maximum value of group velocity and its effect upon the beginning of the Rayleigh-wave train will be the subject of a subsequent paper. It is expected that when a Rayleigh-wave dispersion curve for oceanic crust covering the full range up to periods of 75 sec. becomes available, it too will meet the short-period limit of the mantle Rayleigh-wave dispersion curve, for, as pointed out previously, this limit represents the shortest wave

\footnotetext{
8 Maurice Ewing and Frank Press, "Geophysical Contrasts between Continents and Ocean Basins," "Crust of the Earth," Geol. Soc. Am., Special Papers 62 (1955).

${ }^{9}$ Frank Press and Maurice Ewing, "Earthquake Surface Waves and Crustal Structure," in "Crust of the Earth," Geol. Soc. Am., Special Papers 6\% (1955).

in "Mantle Rayleigh Waves..." (as cited in note 3 above).
} 
length for which continental and oceanic crust are indistinguishable as far as Rayleigh-wave transmission is concerned.

In the period range from 18 sec. to 30 sec., the observed points lie above the theoretical curve by amounts ranging up to $0.2 \mathrm{~km} / \mathrm{sec}$, and it appears that the observed minimum of group velocity is at about 17 sec., in comparison with the value $22 \mathrm{sec}$. for the theoretical curve. Both of these effects would be produced if the contrast in velocity across the Mohorovičic discontinuity were smaller than is assumed. Since the velocities for the top of the mantle are fairly well established, and those for the bottom of the crust are inherently difficult to observe by bodywave studies, we interpret this discrepancy as an effect introduced by an increase of velocity with depth in the crust.

It is clear that a new theoretical dispersion curve is needed, one which includes the effect of an increase of velocity with depth in the crust and in the mantle. Numerical solution of this problem is exceedingly difficult, but the principal features of the result to be expected might be inferred from existing solutions in which a gradient is put in one or the other of the two media separately. The problem is under study as part of the seismic-model program of this laboratory, in which the model is being used as an analog computer.

Rayleigh waves with periods less than 10 sec. could not be found on the seismograms. The impulsive character of the beginning of the 10-sec. Rg wave train, particularly noticeable on the seismogram of the aftershock, strongly suggests that a maximum of group velocity exists for periods in the neighborhood of 10 sec. Since the limiting value of Rayleigh-wave group velocity as the period approaches zero is fixed at about $3.22 \mathrm{~km} / \mathrm{sec}$, it follows that there must be at least one minimum of group velocity in the period range $0-10$ sec., at which the value of group velocity is less than 3.0. It is possible that, owing to variations in sedimentary layers and other near-surface irregularities, the part of the curve for periods between 0 and perhaps 6 sec. may never be observed in a way that will give it continentwide validity. It is probable that attenuation effects of the superficial irregularities limit long-range transmission of waves for periods less than some limiting value below 10 sec., and that a short-period limit for long-range continental transmission similar to the short-period limit at 75 sec. for mantle-wave transmission may exist. As a result of the maximum of group velocity at $T=10 \mathrm{sec}$., $U=$ about $3.0 \mathrm{~km} / \mathrm{sec}$, , the short-wave length limit would occur on the seismogram in a region where strong waves of slightly longer period would probably obscure it. It seems that the best and perhaps the only effective method for studying Rayleigh-wave dispersion for periods less than about 10 sec. is to use near earthquakes or large explosions and considerably shorter paths and shorter-period instruments.

The simplicity in the Rayleigh-wave train can only be demonstrated when complications due to reflected or transformed waves (principally from continental boundaries) are recognized and excluded. In fact, absence of such reflections would pose a serious problem, since it has been shown that for surface waves of any type having periods less than $10 \mathrm{sec}$. continental margins are very effective barriers. ${ }^{11}$ From the

${ }^{11}$ Maurice Ewing and Frank Press, "Propagation of Elastic Waves in the Ocean with Reference to Microseisms," Semaine d'Etude sur le Problème des Microseismes, Pont. Acad. Scient. Scripta Varia, pp. 121-127 (1952). 
seismograms it can be seen that the first major $\mathrm{Rg}$ reflection at $44 \mathrm{~min}$. 50 sec., and the numerous subsequent smaller arrivals out to a travel time of about $54 \mathrm{~min}$., all have a period of about $10 \mathrm{sec}$. Obviously we must either conclude that rather low velocities of propagation are possible for this period, or that, by reflections from barriers, these waves have traveled paths the length of which significantly exceeds that of the great circle path. The time delay of the strong reflection arriving at 44 min. 50 sec. is proper for a path increment of about $250 \mathrm{~km}$., which roughly could correspond to reflection from the continental edge in the vicinity of the epicenter, in the vicinity of the seismograph station at Pietermaritzburg, or somewhere near the Gulf of Guinea.

The velocity of the Lg phase (marked on the seismograms) is $3.46 \mathrm{~km} / \mathrm{sec}$. This is slightly less than the value 3.51 found for North America and 3.54 for Eurasia, possibly because of the inability of the long-period seismograph to record the shortperiod waves which initiate $\mathrm{Lg}$. Although the precise mechanism of $\mathrm{Lg}$ propagation is still uncertain, there is general agreement that a wave guide in the upper part of the crust is responsible for it. The agreement to within 2 per cent of the Lg value observed here with that previously found for North America and Eurasia supports the conclusion of identity in crustal structure for the three continents involved, even in the upper portion of the crust.

\section{ACKNOWLEDGMENTS}

It is a pleasure to acknowledge the coöperation of Dr. P. G. Gane of the Bernard Price Geophysical Institute in Johannesburg and Professor A. N. Fairbrother and Mr. W. L. Mouton at the University of Natal in Pietermaritzburg.

Lamont Geologrcal Observatory

(Columbia UntVersity)

Contribution No. 191
F. P. Now at

Seismological Laboratory

California Institute of Technology 